\title{
AS DIFICULDADES PARA A QUALIFICAÇÃO DO DOCENTE NO ENSINO SUPERIOR PRIVADO E A FRAGILIDADE DA LEGISLAÇÃO NA SUA TUTELA
}

\section{THE DIFFICULTIES FOR THE QUALIFICATION OF TEACHERS IN PRIVATE UNIVERSITY AND THE WEAKNESS OF THE LEGISLATION IN ITS PROTECTION}

Eric José Migani ${ }^{1}$

\begin{abstract}
RESUMO
O presente artigo busca discutir as dificuldades para qualificação do professor que atua no ensino superior em instituições de ensino privado frente à falta de políticas institucionais que viabilizem sua formação acadêmica. O texto aborda a ausência de políticas institucionais que permitam aos professores afastarem-se de suas atividades e, mediante remuneração, cursarem mestrado e doutorado. Ainda, apresenta a legislação trabalhista que tutela a docência, apontando as fragilidades com relação à proteção do professor durante a qualificação. As instituições exigem formação e produção acadêmica sem oferecer suporte financeiro e afastamento remunerado das atividades, omitindo a legislação e jurisprudência sobre a questão.
\end{abstract}

Palavras - chave: Educação superior. Formação docente. Tutela legislativa ao professor.

\section{ABSTRACT}

This paper aims to discuss the difficulties for teacher qualification acting in higher education in private setting, view of the lack of institutional policies that support this education and legislation guaranteeing minimum conditions for this. The institutions require training and academic production without offering financial support and remoteness of paid activities, omitting the legislation and case law on the issue

Key words: Higher education. Teacher education. Legislative protection to the teacher.

\footnotetext{
${ }^{1}$ Mestrando da Faculdade Autônoma de São Paulo - FADISP, área de concentração Função Social do Direito. Professor da Universidade do Tocantins - UNITINS e Faculdade Serra do Carmo FASEC. Advogado.
} 


\section{CONSIDERAÇÕES INICIAIS}

O presente trabalho propõe analisar a relevância da formação continuada na construção dos saberes docentes. Busca também, refletir sobre o perfil do professor para as exigências atuais mercadológicas e o comportamento legislativo e jurisprudencial quanto à tutela jurídica conferida ao professor.

O objetivo principal do artigo é demonstrar os desafios enfrentados pelos professores para qualificarem-se, cumulando as atividades docentes com a formação acadêmica e a maneira como a lei e a jurisprudência tutelam esse trabalhador.

A metodologia empregada será a bibliográfica, com estudo do referencial teórico sobre o tema central, com ênfase nas reflexões empíricas, comparando-as com as doutrinas sobre a matéria. Dividiu-se o trabalho em duas seções.

A primeira seção tratará dos desafios para a qualificação do ensino superior no Brasil, apontando as contradições entre a realidade utilizada nas instituições privadas e as práticas desenvolvidas.

A segunda parte dedica-se a especificar as regras previstas na legislação, em especial a Consolidação das Leis do Trabalho e o posicionamento dos tribunais superiores na proteção dos direitos trabalhistas do professor, que não vinculam diretamente direitos à formação profissional, mas buscam garantir o mínimo de para desenvolverem suas atividades com dignidade.

Por fim, o artigo contribui para a discussão da qualidade e formação da atividade docente, principalmente nas instituições de ensino privado, que exigem constante formação dos docentes sem promover, para isso, as condições mínimas, bem como expõe a omissão do legislador em enfrentar o tema.

\section{OS DESAFIOS PARA QUALIFICAÇÃO DO PROFESSOR NO ENSINO SUPERIOR NO BRASIL: CONTRADIÇÕES ENTRE A REALIDADE E O DEVER SER}

A formação para docência universitária foi negligenciada ao longo do tempo nos planos de estruturação da educação no país, sendo que para tornar-se professor bastava ter o conhecimento específico na área ensinada. Geralmente a 
educação era feita pelos profissionais que atuavam na área, sem formação adequada para o ensino.

Com o advento da Consolidação das Leis do Trabalho - CLT em 1943 foram estipulados como requisito para atuação como professor apenas habilitação legal e registro no Ministério da Educação. Posteriormente, com a Lei de Diretrizes e Bases para Educação determinou-se que para atuação no magistério superior o docente deveria ter formação stricto sensu em mestrado, doutorado e pós doutorado.

Até o início da década de 70 a educação superior era restrita aos grupos abastados da sociedade, que não questionavam os caminhos pedagógicos desenvolvidos em sala de aula, dada a valorização social do profissional que exercia a função. Além da educação superior ser restrita às pessoas com condições econômicas favoráveis para custear sua formação, não se questionava a formação do docente no sentido de aprimorar a forma como o conhecimento era transmitido, os caminhos metodológicos que pudessem levar a uma maior compreensão do conhecimento. (PENIN, 2008).

A profissionalização do professor é um dos desafios contemporâneos da educação, de fortalecimento da profissão e valorização do profissional, sendo incompatível com a qualidade do ensino o professor que não é profissionalmente docente, deixando o improviso e abrindo novas perspectivas para o professor profissional, como explica Bernadete A. Gatti (2010, p. 1360),

Entendemos, com Ramalho, Nuñez e Gauthier (2003), que a profissionalidade é o conjunto de características de uma profissão que enfeixam a racionalização dos conhecimentos e habilidades necessárias ao exercício profissional, e que a profissionalização de professores implica a obtenção de um espaço autônomo, próprio à sua profissionalidade, com valor claramente reconhecido pela sociedade.

A profissionalização do professor além de valorizar a própria educação, um dos pilares da nação, confere maior credibilidade ao profissional e seu mister, deixando de lado o professor não profissional, que atua no magistério superior sem compromisso, como um bico, o qual desenvolve a atividade de forma secundária e não priorizada, para abrir caminho para professores que tenham na educação sua atividade principal. 
A profissionalização implica uma formação inicial na docência acompanhada de formação continuada, preferencialmente oferecida pelas instituições de ensino superior ao qual mantém vínculo profissional, de modo a qualificar e conferir autonomia à docência. Os planos de carreira, cargo e salários são exemplos de instrumentos oferecidos pelas instituições como forma de incentivo à formação, pois associam à qualificação à melhoria salarial.

Com relação às instituições de ensino superior a consequência positiva de ter em seus quadros professores qualificados e com dedicação exclusiva é a possibilidade de colocá-las em patamares de excelência frente às instituições que não investem nos seus profissionais, tornando-se um diferencial no mercado, para as instituições privadas, e referência para as instituições públicas.

Os cursos de licenciatura, em especial a Pedagogia, buscam a formação de professores polivalentes para atuação no ensino básico, médio, educação especial e técnico. Os professores que atuam no ensino superior, com exceção dos cursos de licenciatura, não recebem formação para práticas metodológicas de ensino. Parte-se do pressuposto que se é bom profissional, será bom educador.

A experiência no ensino superior mostra frequentes relatos dos acadêmicos de professores com arcabouço teórico e prático, mas com dificuldade em trabalhar esses conhecimentos em sala de aula, repassá-los aos alunos. Essa deficiência em descobrir caminhos para facilitar o diálogo entre professor e aluno poderia ser superada com a formação do profissional. Essa dificuldade expõe a fragilidade na formação dos quadros do ensino superior, que não atinge apenas as instituições privadas, mas também as instituições de ensino superior públicas. Todavia, o foco desse artigo é relatar as dificuldade de formação de professores nas instituições privadas de ensino superior.

As instituições não investem na preparação pedagógica dos professores universitários em razão da característica pragmática do ensino, alicerçada sobre a máxima "quem soubesse fazer, saberia automaticamente ensinar", não havendo preocupações mais específicas com a necessidade do preparo pedagógico do professor. (MASETTO, 1998, p. 11).

A fragilidade do docente que não é habilitado no curso de pedagogia para enfrentar as dificuldades do dia a dia, como a aplicação de metodologias ativas em sala de aula, mecanismos de avaliação, incorporação de novas tecnologias e bases para desenvolvimento da pesquisa e extensão pode ser sanada por meio do 
implemento de especializações para docência. Assim, o médico, jurista, enfermeiro, engenheiro que pretende formar-se professor do ensino superior, poderá iniciar sua formação para a docência com cursos semelhantes à pedagogia, só que voltados para o ensino superior.

O Ministério da Educação estabelece diretrizes para autorização de funcionamento e manutenção dos cursos de ensino superior, estabelecendo regras que vão desde às instalações físicas à titulação dos docentes. Um conjunto de elementos são avaliados pelo Ministério da Educação para que os cursos de graduação sejam ofertados.

O próprio Ministério oferece cursos voltados para formação docente, com ênfase na educação básica. Para o ensino superior, o Ministério confere incentivos como o "programa de Concessão e Manutenção de Bolsas de Pós-Graduação no País", consistindo em uma "ação de fomento da CAPES para a concessão de bolsas de estudo e custeio para o desenvolvimento da pós-graduação brasileira", programa criado em 1951 e em vigor até hoje. (BRASIL, Ministério da Educação, 2014).

Ainda, com ênfase na formação de professores do ensino superior, 0 Ministério oferece por meio da Comissão de Aperfeiçoamento de Pessoal do Nível Superior - CAPES, oferece o "Programa de Apoio a Eventos no País (PAEP)", com objetivo de impulsionar eventos científicos e tecnológicos para educação superior e básica. Oferece também o "Programa de Cooperação Internacional e Bolsas no Exterior" buscando a formação acadêmica de profissionais de alto nível, "Escola de Altos Estudos" o qual possibilita a vinda de professores estrangeiros para o Brasil, a fim de ministrar cursos de curta duração, dentre outros programas específicos para o campo e diversidade. (BRASIL, Ministério da Educação, 2014).

Ocorre que esses programas federais, disponibilizados para as instituições públicas e privadas, não abarcam toda a demanda relacionada à formação docente, alcançando um grupo muito restrito de professores.

O Censo da Educação Superior de 2011 (ALVAREZ, 2013) aponta que no Brasil há 2.365 Instituições de Ensino Superior, sendo que desse percentual 88\% são instituições privadas, ou seja, instituições que arrecadam recursos diretamente dos alunos e por meio de financiamentos públicos como o FIES - Fundo de Financiamento Estudantil, devendo converter parte da sua arrecadação orçamentária na formação dos profissionais. Os programas oferecidos pela CAPES seriam subsidiários ao investimento das instituições privadas, ficando a cargo de 
cada instituição reservar parte do orçamento para formação e qualificação docente. Todavia essa não é a realidade vivenciada nas instituições de ensino da rede privada.

A Lei no 10.861 de 14 de abril de 2014 institui o SINAES - Sistema Nacional de Avaliação do Ensino Superior, com objetivo de avaliar as instituições de ensino superior, institui critérios que tem por escopo a melhoria na qualidade de ensino. Dentre esses parâmetros aferidos pelo Instituto Nacional de Estudos e Pesquisas Educacionais - INEP está a formação e qualificação docente.

As instituições pontuam à medida que investem no docente, nos termos do art. $3^{\circ}, \mathrm{V}$ da referida lei "Art. $3^{\circ} \mathrm{A}$ avaliação das instituições de educação superior terá por objetivo identificar o seu perfil e o significado de sua atuação, por meio de suas atividades, cursos, programas, projetos e setores, considerando as diferentes dimensões institucionais, dentre elas obrigatoriamente as seguintes: as políticas de pessoal, as carreiras do corpo docente e do corpo técnico-administrativo, seu aperfeiçoamento, desenvolvimento profissional e suas condições de trabalho". (BRASIL, SINAES, Lei $\mathrm{n}^{\circ} 10.861$ de 14 de abril de 2004).

Para atender às exigências do INEP e MEC as instituições de ensino privado exigem dos professores titulação sem oferecer, em contrapartida, auxílio financeiro e afastamento das atividades profissionais. Em outras palavras, o gargalo da formação profissional recaí exclusivamente sobre o professor, que para manter-se ativo nas instituições de ensino superior privado cumulam qualificação com sala de aula, levando à fadiga e queda no rendimento profissional e na qualificação.

A capacitação deverá ocorrer tanto nas instituições públicas como nas privadas. As Universidades públicas possuem plano para qualificação, licenciando o professor que pretende qualificar-se. Ainda, como meio de progressão na carreira, as universidades públicas exigem do professor um contínuo aperfeiçoamento e oferecem a opção pela dedicação exclusiva, com acréscimo salarial.

Por seu turno, as instituições privadas, em sua grade maioria, não investem na capacitação do professor, exigindo melhoria na sua qualidade e titulação, sem oferecer contrapartida. Assim, cabe ao professor, cumular as atividades de qualificação e docente, tendo como consequência queda na qualidade do ensino e baixo aproveitamento nos cursos de qualificação - mestrado, doutorado e pós doutorado. 
Além do acúmulo de atividades, o professor acaba onerando-se com a qualificação, pois os cursos stricto sensu em universidades públicas não comportam toda a demanda do mercado, buscando o professor qualificar-se nas instituições privadas. A partir daí começam os problemas de saúde, acúmulo de atividades, stress e baixa no rendimento, tanto da qualificação quanto das atividades profissionais.

A qualidade na formação dos professores que atuam em nível superior envolve peculiaridades que o diferenciam dos professores que atuam nos níveis fundamental e médio, devendo ser levado em consideração o público alvo, qual seja, pessoas adultas, com personalidade formada, com carga ideológica e vivência que influenciam na dialética em sala de aula. A necessidade de constante atualização e largo arcabouço de conhecimento se torna ainda maior, dada a exigência mais acurada do alunado.

A capacitação de professores que atuarão em nível superior é complexa, envolta em uma cultura docente cheia construída a partir das "relações profissionais, sociais, afetivas e culturais" (NUNES; MONTEIRO, 2007, p. 23), primeiro porque se trata de um profissional que atuará com um público de alunos adulto, com exigências em sala de aula diferenciadas dos níveis iniciais, e ainda, trata-se de professores com identidade do profissional formada, levando para sala de aula sua carga ideológica, cultural e pessoal.

Nunes e Monteiro (2007, p. 22-23) destacam a formação do professor a partir da profissionalização e cultura docente, cuja relação é "impregnada de tensões, contradições e potencialidades",

A produção de uma cultura profissional dos professores é um trabalho longo, realizado no interior e no exterior da profissão, que obriga a intensas interações e partilha. (NÓVOA, 1991, p. 27 apud NUNES; MONTEIRO, 2007, p. 23).

A profissionalização da docência no Brasil enfrenta muitos entraves principalmente relacionado à desvalorização do professor relacionada principalmente à baixa remuneração e condições precárias de trabalho. Esse ambiente desvaloriza a docência e não estimula a profissionalização do professor de nível superior. Ainda, o professor acaba por cumular várias atividades para complementar a renda, comprometendo ainda mais esse cenário. 
Além dos aspectos pessoais do professor e do alunado, a formação perpassa também pelas diretrizes estabelecidas no Projeto Político Pedagógico (PPP) de cada curso, o qual é elaborado em consonância com a Lei de Diretrizes e Bases da Educação, que em relação à atuação no ensino superior exige no art. 66 "A preparação para o exercício do magistério superior far-se-á em nível de pósgraduação, prioritariamente em programas de mestrado e doutorado". (BRASIL, Lei de Diretrizes e Bases da Educação).

A atuação em nível superior não exige preparação pedagógica específica, principalmente para os desafios em sala de aula, mas conhecimento na área de atuação e formação stricto sensu. Aqui reside uma fragilidade na formação do professor e que demanda uma mudança da política educacional macro adotada no país, de revalorização da carreira e humanização da relação professor, aluno e instituição.

Assim, os principais desafios relacionados à profissionalização do professor de ensino superior pauta-se na mudança na cultura docente, com a revalorização da profissão, incluindo melhor remuneração, planos de formação continuada promovidos pelas Instituições de Ensino Superior público e privada e melhores condições estruturais que valorizem o ambiente do trabalho e a relação aluno e professor.

Paulo Freire (1996, p. 94) ressalta o valor do educador como ser humano, inserido no contexto social comunitário, de pessoas ligadas por valores que extrapolam a transmissão de conteúdo, "me movo como educador, porque primeiro me movo como gente", situação que revela a relevância da formação docente holística, humanizada,

A legislação é um importante instrumento na consolidação da carreira docente, mas por si só não é capaz de promover sua revalorização. A lei tutela a jornada de trabalho e demais direitos do professor enquanto trabalhador, garante autonomia aos sindicatos e prevê, na Constituição Federal, diretrizes especiais para educação, mas não vincula o dever das instituições em garantir condições mínimas para sua qualificação. 


\section{A LEGISLAÇÃO E O POSICIONAMENTO DOS TRIBUNAIS QUANTO À TUTELA DOS DIREITOS DO PROFESSOR}

Essa seção tratará dos principais direitos relacionados à tutela do professor, pois mesmo inexistindo lei que vincule as instituições de ensino ao dever de capacitar o docente, criando mecanismos financeiros e dispensa das atividades laborais, cuidam de algumas regras que garantem o mínimo de condições para desenvolverem suas atividades. Ainda, mostrará os pontos na legislação e jurisprudência que prejudicam o trabalhador da educação, dificultando ainda mais dispor de tempo para sua formação.

A oferta de ensino superior no Brasil está regulada pela Constituição da República Federativa do Brasil, a qual dispõe sobre os princípios da educação, a Lei no 9.394/96 Lei de Diretrizes e Bases da Educação; a Lei no 10.861/2004 que institui o SINAES - Sistema Nacional de Avaliação do Ensino Superior; Decreto 5.773, de 9/5/2006: dispõe sobre as funções de regulação, supervisão e avaliação da educação superior; Portaria no 40, de 12 de dezembro de 2007 que institui o e-MEC, sistema eletrônico de fluxo de trabalho e gerenciamento de informações relativas aos processos de regulação da educação superior no sistema federal; Portaria Normativa ํo 1, de 10/01/2007 que define o ciclo avaliativo do Sinaes; Portaria Normativa 4, de 07 de agosto de 2008 a qual regulamenta a aplicação do conceito preliminar de cursos superiores - CPC, para fins dos processos de renovação de reconhecimento; a Portaria Normativa 12, de 08 de setembro de 2008 que Institui o Índice Geral de Cursos da Instituição de Educação Superior (IGC); a Portaria Normativa 10, de 03 de julho de 2009 que fixa critérios para dispensa de avaliação in loco. (BRASIL, Ministério da Educação, 2014)

Todos esses instrumentos, direta ou indiretamente, influenciam na atividade docente, pois regulam a educação em parâmetros nacionais. A legislação também cuida especificamente do trabalhador professor, tutelando as condições de trabalho e demais direitos trabalhistas, regras previstas na Consolidação das Leis do Trabalho.

A legislação não está alheia às fragilidades da profissão, fixando um mínimo de direitos, deixando para as Convenções Coletivas estabelecer melhores condições de trabalho. Em razão da peculiaridade do trabalho exercido pelo professor a CLT 
tratou na seção XII artigos 317 a 324, constituindo que a sua jornada de trabalho é diferenciada, uma vez que poderá ministrar no máximo quatro horas-aulas consecutivas ou seis-horas aula alternadas, além de ter que respeitar um período de interjornada de onze horas entre um dia de trabalho e outro.

Em face do grande desgaste físico e intelectual do docente a lei limitou a carga de trabalho do professor em quatro horas/aula consecutivas ou seis intercaladas por dia, em um mesmo estabelecimento de ensino. Esta medida também favorece um ensino mais eficiente. (CASSAR, 2011).

A Constituição Federal autoriza a cumulação de mais de um cargo para os profissionais da educação, o que resulta em longas jornadas de trabalho, comprometendo o rendimento do trabalho e a saúde do trabalhador. Esse é o primeiro aspecto negativo da legislação, pois as instituições de ensino aproveitam dessa abertura para sobrecarregar o professor, que se submete a extensas jornadas a fim de melhorar seus rendimentos. Cria-se um círculo vicioso na educação, baixa remuneração do profissional com extensa carga horária de trabalho.

No intuito aumentar a renda, os professores assumem exaustiva e penosa jornada de trabalho, cumulando até 60 (sessenta) horas semanais, laborando diariamente nos períodos matutino, vespertino e noturno, sem contar as aulas em cursos de pós-graduação, que geralmente acontecem aos finais de semana.

Além da longa jornada de trabalho, o professor precisa qualificar-se, o que na rede privada acontece cumulativamente às atividades profissionais. Se de um lado temos o excesso de trabalho com baixa remuneração, de outro tem-se a exigência constante das instituições para que o professor invista na sua formação, principalmente que obtenha titulação de mestrado e doutorado. Frente a essa demanda constante pela formação e a pressão das instituições privadas por qualificação docente questiona-se: em que momento esse trabalhador se dedicará à qualificação profissional? $\mathrm{O}$ excesso de atividades compromete a saúde do trabalhador?

Ressalta-se que quando se trata de nível superior há uma cobrança para os docentes nesse sentido, mas poucas instituições particulares viabilizam ajuda financeira e/ou redução da jornada de trabalho, pelo contrário, a qualificação profissional torna-se uma condição sine qua non para que o professor mantenha o 
seu emprego, além de provocar desgaste físico e emocional, comprometendo sua saúde.

Assim, em razão da concorrência mercadológica entre as instituições de ensino particular cada vez mais paga-se menos ao profissional da educação e exigese boa qualificação. A CLT exige que o professor seja remunerado dignamente, dada a relevância da sua função no desenvolvimento social e econômico da nação. A educação é o pilar de todas as outras profissões e, quando comparada com outras carreiras, percebe-se o quanto está desvalorizada.

Art. 323 - Não será permitido o funcionamento do estabelecimento particular de ensino que não remunere condignamente os seus professores, ou não thes pague pontualmente a remuneração de cada mês.

Parágrafo único - Compete ao Ministério da Educação e Saúde fixar os critérios para a determinação da condigna remuneração devida aos professores bem como assegurar a execução do preceito estabelecido no presente artigo.

As instituições de ensino superior optam por professores com menor titulação ou apenas professores especialistas, a fim de baratear os custos, remunerando sempre a menor do que expressa a palavra condignamente. O Ministério da Educação e seus órgãos de fiscalização não estão enfrentando a precariedade do ensino superior com rigor, permitindo a abertura de cursos e faculdades sem as condições mínimas de estrutura e corpo docente qualificado. Em síntese, as instituições privadas remuneram mal o professor, exigindo dele constante qualificação sem oferecer as condições mínimas de salário e afastamento das atividades para isso.

Ainda, o professor de instituição de ensino superior privada recebe carga horária quase que exclusiva em sala de aula, visto o baixo incentivo em pesquisa e extensão, realizando as atividades de preparação de aula, correção de trabalhos e avaliações e demais atividades inerentes à função no seu horário de folga, sem remuneração adicional - esse é o entendimento dos Tribunais Trabalhistas, que atividade extraclasse não deve ser remunerada, pois já está inclusa no valor da hora-aula - . A essa rotina exaustiva serão acrescidas das atividades de qualificação, levando o professor ao assoberbamento de tarefas e desenvolvimento de doenças.

A CLT limita a quatro horas consecutivas ou seis intercaladas no mesmo estabelecimento, nos termos do art. 318 da CLT "Num mesmo estabelecimento de 
ensino não poderá o professor dar, por dia, mais de 4 (quatro) aulas consecutivas, nem mais de 6 (seis), intercaladas". A leitura que se extraí do dispositivo é que o empregador não poderá realizar vários contratos de trabalho com o professor a fim de burlar a lei, pois onde se lê "estabelecimento" entenda-se "empregador". (CASSAR, 2011).

A Orientação Jurisprudencial do Tribunal Superior do Trabalho é no sentido que as horas extraordinárias, excedido o teto legal da jornada, deverão ser remuneradas com adicional de $50 \%$, nos termos do art. $7^{\circ}, \mathrm{XVI}$ da CRFB. Vejamos a Orientação Jurisprudencial nำ206.

OJ n. 206

PROFESSOR. HORAS EXTRAS. ADICIONAL DE 50\% (inserida em 08.112000).

Excedida a jornada máxima (art. 318 da CLT), as horas excedentes devem ser remuneradas com o adicional de, no mínimo, 50\% (art. 7º, XVI, CF/1988). (BRASIL, Tribunal Superior do Trabalho, SDI - I).

A jurisprudência afasta Acordo ou Convenção coletiva que desonera o empregador da remuneração do adicional por hora extraordinária de trabalho:

RECURSO DE REVISTA. PROFESSOR. PAGAMENTO DE HORAS EXTRAS. SUPRESSÃO DO ADICIONAL DE $50 \%$ CONTEMPLADA EM NORMA COLETIVA. A tutela especial prevista no artigo 318 da CLT tem por finalidade evitar o desgaste físico e mental do educador, promovendo um ensino mais eficiente e promissor. Ainda que esta Corte adote entendimento no sentido de conferir validade ampla à negociação coletiva, não se pode admitir que a norma coletiva suprima direitos referentes à jornada de trabalho do professor, que ostenta legislação específica. Nesse sentido se direciona a Orientação Jurisprudencial 206 da SBDI-1/TST, quando dispõe que: "Excedida a jornada máxima (art. 318 da CLT), as horas excedentes devem ser remuneradas com o adicional de, no mínimo, 50\% (art. 7º, XVI, CF/88)." A exclusão do adicional de 50\% desonera o empregador, que não se constrangerá em impor jornada que exceda o limite legal. Esta é a hipótese em que se faz necessário tutelar o trabalhador, ainda que contra os seus interesses imediatos.(...) Recurso de Revista parcialmente conhecido e provido." (BRASIL, Tribunal Superior do Trabalho, RR - 47000-84.2002.5.15.0033 , Relator Ministro: Horácio Raymundo de Senna Pires, Data de Julgamento: 11/11/2009, 3ª Turma, Data de Publicação: 27/11/2009, grifo nosso)

Outra questão importante para qualidade do professor e da sua aula é o tempo em sala de aula. A hora enquanto marco temporal tem duração de 60 minutos, tratando-se de uma unidade de tempo. A hora - aula é um conceito 
acadêmico, podendo a instituição de ensino optar por um tempo de relógio menor, exemplo 40 minutos, possibilitando ao professor dedicar os outros 20 minutos para preparação de material, correção de provas etc.

É importante frisar que hora e hora-aula não são termos sinônimos. Hora é um segmento de tempo equivalente ao período de 60 (sessenta) minutos. Hora - aula corresponde a hora de atividade ou de trabalho escolar efetivo, sendo esse, portanto um conceito estritamente acadêmico, ao contrário daquele, que é uma unidade de tempo. (CASSAR, 2011).

Na hipótese do professor ministrar mais de quatro horas - aula sem intervalo, fará jus ao adicional de $50 \%$ a partir da quarta hora nos termos do art. 318 da CLT. A mesma regra incide na hipótese do professor ultrapassar as seis horas-aula intervaladas com um descanso.

Não se pode olvidar que a mercantilização da educação afetou diretamente a atividade docente, cuja lógica a considera um produto, apto a gerar lucro, e explorar a mais valia do trabalhador. Associado às questões de exploração da educação como mercadoria estão outros elementos que interferem no desempenho docente, como a desvalorização da docência enquanto carreira, o isolamento profissional, o individualismo e o estresse consequente do excesso de atividade em sala de aula.

O Tribunal Superior do Trabalho tem reconhecido alguns direitos aos professores que aumentam a proteção ao trabalho docente. Dentre eles, o direito a ter aviso prévio remunerado em momento que não coincida com as férias escolares e o direito ao repouso semanal remunerado com o acréscimo de 1/6 dos rendimentos e salário mínimo como piso remuneratório:

Súmula $n^{\circ} 10$ do TST

PROFESSOR. DISPENSA SEM JUSTA CAUSA. TÉRMINO DO ANO LETIVO OU NO CURSO DE FÉRIAS ESCOLARES. AVISO PRÉVIO (redação alterada em sessão do Tribunal Pleno realizada em 14.09.2012) - Res. 185/2012, DEJT divulgado em 25, 26 e 27.09.2012

O direito aos salários do período de férias escolares assegurado aos professores (art. 322, caput e $\S 3^{\circ}$, da CLT) não exclui o direito ao aviso prévio, na hipótese de dispensa sem justa causa ao término do ano letivo ou no curso das férias escolares. (BRASIL, Tribunal Superior do Trabalho, Súmulas).

Súmula no 351 do TST

PROFESSOR. REPOUSO SEMANAL REMUNERADO. ART. $7^{\circ}, \S$ 2을 DA LEI № 605, DE 05.01.1949 E ART. 320 DA CLT (mantida) Res. 121/2003, DJ 19, 20 e 21.11.2003 
O professor que recebe salário mensal à base de hora-aula tem direito ao acréscimo de 1/6 a título de repouso semanal remunerado, considerando-se para esse fim o mês de quatro semanas e meia. (BRASIL, Tribunal Superior do Trabalho, Súmulas).

OJ 244/SDI-I/TST. 393. PROFESSOR. JORNADA DE TRABALHO ESPECIAL. ART. 318 DA CLT. SALÁRIO MÍNIMO. PROPORCIONALIDADE. (DEJT divulgado em 09, 10 e 11.06.2010) A contraprestação mensal devida ao professor, que trabalha no limite máximo da jornada prevista no art. 318 da CLT, é de um salário mínimo integral, não se cogitando do pagamento proporcional em relação a jornada prevista no art. $7^{\circ}$, XIII, da Constituição Federal. (BRASIL, Tribunal Superior do Trabalho, SDI - I).

O repouso semanal remunerado tem por objetivo proporcionar ao trabalhador repor suas energias, sob três aspectos: físico, social e econômico. O aspecto físico refere-se à fisiologia do trabalhador, conferindo saúde e bem estar. Quanto ao aspecto social, o trabalhador terá garantido um tempo para convívio familiar e social, indispensável ao ser humano. Por último, o trabalhador saudável físico e emocional rende mais, produz com mais qualidade, sendo bom para o empregado, empregador e o desenvolvimento econômico do país.

O descanso semanal remunerado de 24 horas, preferencialmente aos domingos, está previsto na Lei nº 605/49 e artigo 67 da CLT, exigindo-se frequência e pontualidade do trabalhador para seu gozo. Logo, perderá o direito à remuneração do descanso o professor que faltar ou se atrasar injustificadamente. Contudo, poderá gozar do descanso, mas sem a remuneração prevista na lei. Trata-se de uma regra geral aplicadas a todos os trabalhadores.

Todo trabalhador, incluindo-se o professor, fará jus ao descanso de 11 horas ente uma jornada e outra de trabalho, denominado repouso Interjornada, previsto no artigo art. 66 da CLT "art. 66 - Entre 2 (duas) jornadas de trabalho haverá um período mínimo de 11 (onze) horas consecutivas para descanso". (BRASIL, Consolidação das Leis do Trabalho).

A alteração contratual é outro ponto importante tutelado pela legislação, evitando alterações injustificadas e unilaterais que prejudiquem o trabalhador. A CLT, como regra geral, veda a alteração do contrato de trabalho, podendo ser alterado excepcionalmente, desde que não prejudique o trabalhador, nos termos do art. 468 da CLT 
Art. 468 - Nos contratos individuais de trabalho só é lícita a alteração das respectivas condições por mútuo consentimento, e ainda assim desde que não resultem, direta ou indiretamente, prejuízos ao empregado, sob pena de nulidade da cláusula infringente desta garantia.

A alteração poderá ser feita desde que não moleste o trabalhador e haja mútuo consentimento. Todavia, o empregador poderá fazer pequenas alterações no contrato de trabalho desde que não acarrete dano direto ou indireto ao empregado. Assim, com fundamento no poder diretivo, o empregador poderá fazer ajustes no ambiente de trabalho, nos cargos em comissão, locais de prestação de serviços. Isso não implica em alteração do contrato de trabalho e aplica-se aos professores.

A alteração de salário é uma das questões mais enfrentadas pelos professorado quanto ao tema alteração do contrato de trabalho. A Constituição Federal no art. $7^{\circ}$ VI veda a redução de salários, excepcionando por no máximo dois anos quando disposta em convenção ou acordo coletivo.

O Tribunal Superior do Trabalho entende que a redução do número de alunos poderá levar à redução do salário do professor, devendo ser mantida o valor da hora - aula.

OJ 244/SDI-I/TST. 244. PROFESSOR. REDUÇÃO DA CARGA HORÁRIA. POSSIBILIDADE (inserida em 20.06.2001)

A redução da carga horária do professor, em virtude da diminuição do número de alunos, não constitui alteração contratual, uma vez que não implica redução do valor da hora-aula. (BRASIL, Tribunal Superior do Trabalho, SDI - I).

A justificativa aceita para redução do valor da remuneração do professor horista é a redução do número de alunos, devendo ser comprovada a real queda no número de alunos e turmas. Vejamos a jurisprudência do TST:

AGRAVO DE INSTRUMENTO EM RECURSO DE REVISTA PROFESSOR HORISTA - DIFERENÇAS SALARIAIS - REDUÇÃO DA CARGA HORÁRIA. Para que seja lícita a redução da carga horária do professor horista, é necessária a efetiva diminuição do número de alunos na instituição de ensino, nos exatos termos da Orientação Jurisprudencial $n^{\circ} 244$ da SBDI-1 do TST. No caso vertente, não restou comprovada nos autos a real queda na quantidade de alunos, sendo lesiva a redução salarial do autor, conforme norma contida no art. $7^{\circ}, \mathrm{Vl}$, do texto constitucional. É inadmissível recurso de revista em que, para se chegar à conclusão pretendida pela recorrente, seja imprescindível o reexame do arcabouço fático-probatório dos autos, a teor do disposto na Súmula no 126 do TST. Violações e divergência afastadas. Agravo de instrumento desprovido. (BRASIL, Tribunal Superior do Trabalho, 
AIRR-61600-66.2009.5.05.0026 , Relator Ministro: Luiz Philippe Vieira de Mello Filho, Data de Julgamento: 06/06/2012, 4a Turma, Data de Publicação: 15/06/2012).

O professor que se vê obrigado a diminuir sua carga horária com a finalidade de frequentar as aulas de mestrado e doutorado não tem nenhuma garantia legal e jurisprudencial de manutenção do salário.

O Tribunal Superior do Trabalho entendeu que as atividades extraclasse já estão remuneradas na hora - aula recebida pelo professor, não fazendo jus a adicional, ponto negativo da jurisprudência quando trata das atividades docentes. $O$ Tribunal não levou em consideração que o Professor investe horas preparando a aula, sendo que seu desempenho em sala de aula é apenas parte do trabalho empreendido.

PROFESSOR. ATIVIDADE EXTRACLASSE. HORA-ATIVIDADE. Da exegese dos artigos 320 da CLT e 13 da Lei no 9.394/96, conclui-se que a prática de atividades extraclasse, tais como preparo de aula e correção de provas, está incluída nas atribuições normais do professor e na sua remuneração. Portanto, a realização de atividades fora da sala de aula - inerentes à função de professor -, por si só, não implica o pagamento de gratificação ou adicional suplementar. Recurso de revista de que se conhece e a que se dá provimento. (BRASIL, Tribunal Superior do Trabalho. Processo no TST-RR - 30890.2011.5.04.0203).

A legislação é um mecanismo de proteção do professor, mas não é suficiente para mudar a cultura de desvalorização da docência, uma vez que demanda a reestruturação de um sistema que secularmente vem sendo deixado em segundo plano nas ações estatais e agora, sob a ótica mercantilista, é visto como instrumento de lucro, cujas despesas com infraestrura e qualificação docente devem ser reduzidas a fim de cada vez mais receita.

\section{CONSIDERAÇÕES FINAIS}

As relações educacionais são complexas e envoltas em um sistema que abrange vários personagens: educadores, alunos, sociedade, família, instituições de ensino e Estado. A estruturação de um sistema que proporcione a formação de cidadãos é tarefa árdua e exige empenho de todos esses protagonistas, assim como condições sociais e econômicas que favoreçam o desenvolvimento. 
No tocante à formação especifica dos professores de ensino superior, os desafios são muitos, uma vez que envolvem os professores e as instituições que abrigam esse profissional.

As instituições de ensino privada tendem a se valer mais da relação de exploração entre professor e capital, exigindo do professor permanência integral em sala de aula e capacitação, cumulativamente, sem incentivar por meio de auxílio financeiro e afastamento remunerado a formação do profissional, principalmente em busca de melhor titulação - mestrado, doutorado e pós doutorado.

A Constituição permite que o professor acumule mais de uma atividade na área da educação, o que pode ser dois cargos de professor ou um cargo de professor e outro técnico. Essa autorização, acarreta, como consequência nociva à saúde o acúmulo de uma jornada excessiva de trabalho, às vezes de 60 horas semanais, comprometendo a qualidade de vida do profissional.

Aliada à excessiva jornada de trabalho vem a cobrança por uma constante qualificação do profissional, que para atuar no ensino superior necessita ter a titulação de mestre, doutor ou pós-doutor, constante publicação de pesquisas e ensaios científicos, participação em congressos e outras atividades relacionadas à produção acadêmica.

A lógica capitalista das instituições privadas vai na contramão da formação profissional de qualidade, mantendo a saúde do professor, sua qualidade de vida social, econômica e familiar.

A educação no ensino superior trabalha com sujeitos críticos, ativos e, potencialmente, já iniciados no mercado de trabalho, levando para dentro da relação professor-aluno essa experiência de vida.

O professor, em todos os níveis do ensino, não é um mero reprodutor de conteúdo, mas um mediador entre o aluno e o conhecimento, um instrumento do processo de construção do saber.

Os desafios para a formação do professor são muitos e modificam-se a cada período da história, acompanhando as mudanças sociais. Hoje, por exemplo, um desafio a ser implementado na relação de aprendizagem consiste na inserção da tecnologia no contexto educacional. A importância de constante formação do professor o habilita para a utilização das novas tecnologias.

Superar a lógica capitalista, que não investe na formação docente de qualidade, é um dos principais desafios da formação docente, merecendo atenção 
do legislador na criação de mecanismos que vinculem as instituições de ensino superior ao dever de formar seus professores.

\section{REFERÊNCIAS}

\section{ALVAREZ, Ana Maria Torres. Projeto CNE/UNESCO 914BRZ1136.3:}

Desenvolvimento, aprimoramento e consolidação de uma educação nacional de qualidade. UNESCO - Organização das Nações Unidas para Educação, a Ciência e a Cultura; CNE - Conselho Nacional de Educação. São Paulo, 2013. Disponível em: $<$

http://webcache.googleusercontent.com/search?q=cache:2O2TlimEurYJ:portal.mec. gov.br/index.php\%3Foption\%3Dcom_docman\%26task\%3Ddoc_download\%26gid\%3 D13944\%26ltemid\%3D+\&cd=2\&hl=pt-BR\&ct=clnk\&gl=br>. Acesso em: 14 nov. 2014.

BRASIL, SINAES, Lei nำ10.861 de 14 de abril de 2004. Disponível em: <http://portal.mec.gov.br/arquivos/pdf/leisinaes.pdf>. Acesso em: 30 out. 2014.

. Tribunal Superior do Trabalho. Recurso de Revista. Processo no TST-RR 308-90.2011.5.04.0203. Disponível em:

https://aplicaca05.tst.jus.br/consultaProcessual/consultaTstNumUnica.do?consulta= Consultar\&conscsjt=\&numeroTst=308\&digitoTst=90\&anoTst=2011\&orgaoTst=5\&trib unalTst=04\&varaTst=0203\&submit=Consultar. Acesso em: 16 nov. 2014.

. Tribunal Superior do Trabalho, Recurso de Revista.RR - 47000-

84.2002.5.15.0033, Relator Ministro: Horácio Raymundo de Senna Pires, Data de Julgamento: 11/11/2009, 3ª Turma, Data de Publicação: 27/11/2009. Disponível em $<$

https://aplicaca05.tst.jus.br/consultaProcessual/consultaTstNumUnica.do?consulta= Consultar\&conscsjt=\&numeroTst $=47000$ \&digitoTst $=84 \&$ anoTst $=2002 \&$ orgaoTst $=5 \& \mathrm{tr}$ ibunalTst=15\&varaTst=0033\&submit=Consultar $>$. Acesso em: 20 nov. 2014.

. Tribunal Superior do Trabalho. SDI - I. Disponível em < http://www.tst.jus.br/ojs/-/asset publisher/1N7k/content/secao-de-dissidiosindividuais-i-sdi-i> . Acesso em: 20 nov. 2014).

. Tribunal Superior do Trabalho. Súmulas. Disponível em < http://www.tst.jus.br/sumulas> . Acesso em: 20 nov. 2014.

. Tribunal Superior do Trabalho, AIRR-61600-66.2009.5.05.0026, Relator Ministro: Luiz Philippe Vieira de Mello Filho, Data de Julgamento: 06/06/2012, 4ª Turma, Data de Publicação: 15/06/2012. Disponível em: < https://aplicacao5.tst.jus.br/consultaProcessual/consultaTstNumUnica.do?consulta= Consultar\&conscsjt=\&numeroTst=61600\&digitoTst=66\&anoTst=2009\&orgaoTst=5\&tr ibunalTst=05\&varaTst=0026\&submit=Consultar $>$. Acesso em: 21 nov. 2014. 
BERNARDETE A. GATTI. Formação de professores no brasil: características e problemas. In: Educ. Soc., Campinas, v. 31, n. 113, p. 1355-1379, out.-dez. 2010. Disponível em: <http://www.cedes.unicamp.br>. Acesso em: 30 out. 2014.

CASSAR, Vólia Bonfim. Direito do Trabalho. 5 ed. rev. ampl. e atual. Niterói: Impetus, 2011.

FREIRE, Paulo. Pedagogia da autonomia: saberes necessários à prática educativa. São Paulo: Paz e Terra, 1996.

MASETTO, Marcos (Org.). Docência na universidade. Campinas, SP: Papirus, 1998.

NÓVOA, Antônio et al. Os professores e a sua formação. Lisboa, Portugal: Dom Quixote, 1992.

NUNES, Cely do Socorro Costa Nunes; MONTEIRO, Albêni Lis. Profissionalização e Cultura Docente: limites e possibilidades na formação de professores. In: Formação do pesquisador em Educação: profissionalização docente, políticas públicas, trabalho e pesquisa. MERCADO, Luis Paulo Leopoldo; CAVALCANTE, Maria Auxiliadora da Silva Cavalcante (Orgs). 18 ed. Maceió - AL: ed. UFAL. p. 21-36.

PENIN, Sonia Teresinha de Sousa. Profissionalidade: o embate entre o concebido e o vivido. In: EGGERT, Edla et al. Trajetórias e processos de ensinar e aprender: didática e formação de professores. Porto Alegre: EDIPUCRS, 2008. p. 646-662. 